\title{
Neuro-mechanical aspects of playing-related mobility disorders in orchestra violinists and upper strings players: a review
}

\author{
Joseph Mizrahi \\ Department of Biomedical Engineering, Technion, Israel Institute of Technology, Haifa, Israel \\ This article is distributed under the terms of the Creative Commons Attribution Noncommercial License (CC BY-NC 4.0) which permits
} any noncommercial use, distribution, and reproduction in any medium, provided the original author(s) and source are credited.

\begin{abstract}
Orchestra musicians are at high risk of neuro-mechanical disorders due to the intense stresses their body withstand, leading to pain and injury. This review presents a comprehensive account of the works on the circumstances and types of playing related mobility disorders of upper strings players, as well as on the relevant neuro-mechanical factors and perspectives to those disorders. The following aspects are considered: asymmetry and imbalance in the musculo-skeletal system, muscle-bone-joint interactions, repetitive overloading and fatigue. An additional factor relates to neuro-muscular redundancy in the motor system, whereby more muscles and tendons than strictly necessary are engaged in performing a motor task, thus making the system indeterminate, with no unique solution. This same task can be performed with different muscle combinations. It is thus of interest to verify whether playing disorders may be alleviated by considering alternative techniques of performance.
\end{abstract}

Key Words: Playing-related mobility disorders, upper string players, asymmetry, repetitive strain injury, muscle fatigue

Eur J Transl Myol 2020; 30 (3): 9095. doi: 10.4081/ejtm.2020.9095

Of the orchestra musicians, players of the upper string instruments have been reported to be among the most vulnerable to playing related musculo-skeletal disorders (PRMD). ${ }^{1-7}$ More recently, Gembris et al. ${ }^{8}$ reported that, compared to other instruments, string players have an above-average likelihood of suffering from physical problems. Accordingly, violinists are the most frequently studied players and the following physical factors have been cited to contribute to the development of their PRMD: unnatural posture, relatively high loading forces on their limbs and trunk, repetitive movements, vibrations and fatigue. ${ }^{9,10}$ Specifically, in the upper strings players, unnatural and asymmetrical postures are encountered in activating the movements of the arms, hands and fingers. ${ }^{11}$ In addition, these players play almost continually during the performance, which makes them even more prone to fatigue and injury. Data about the high incidence of musculoskeletal disorders in the upper limbs of string players, particularly upper string players are presented in Appendix A. Past work relating PRMD to neuro-mechanical factors has been confined to specific aspects, such as EMG, ${ }^{12-16}$ kinematics of the bowing limb, ${ }^{10,12,14}$ and postural issues. ${ }^{10,17,18}$ This review provides a comprehensive neuro-mechanical perspective of the factors responsible for injuries encountered by orchestra upper strings musicians. Next section deals with the combined action of the muscle-tendon-bonejoint complex on loading of the bones, tendons and joints and how this is affected by muscle imbalance. The repetitive activity of playing induces fatigue and weakening of the muscles resulting in imbalance and altered body posture. A common consequence of imbalance relates to the subacromial impingement syndrome within the rotator cuff which causes considerable discomfort and pain. Third section presents the concept of neuro-muscular redundancy in performing human activity in general and in violin playing, in particular. The redundant muscular activity of each of the upper limbs during upper strings playing is described and the concept of biomechanical indeterminacy is introduced. Fourth section addresses the questions of asymmetry in posture and in function of upper strings players. The consequences of asymmetry are examined in the light of the required playing activities and the coordination between muscle activity and kinematics is discussed. Fifth section is devoted to the loading forces in the tendons and joints of the left hand index finger caused by string fingering, based on direct force measurements and on a biomechanically indeterminate model. The resolution of the forces within the tendons and joints allow to further reveal the cartilage stresses within the joints. The role of the muscles and their attached tendons as shock absorbers is further described 
Table A1. Incidence (\% of tested players) of pain and/or musculo-skeletal disorder by site in the upper limb

\begin{tabular}{|l|l|l|l|l|}
\hline & $\begin{array}{l}\text { Newmark \& } \\
\text { Hochberg }^{116}\end{array}$ & Fry $^{39}$ & $\begin{array}{l}\text { Abreu-Ramos } \\
\text { (Upper Strings) }\end{array}$ & $\begin{array}{l}\text { Lederman }^{64} \\
\text { (Strings only) }\end{array}$ \\
\hline Shoulder & 9 & 35 & 63 & \\
\hline Elbow & 20 & 10 & 20 & \\
\hline Forearm & 40 & 34 & & \\
\hline Wrist & 16 & & 34 & 89 \\
\hline Hand/wrist & & 41 & 29 & $19^{*}$ \\
\hline $\begin{array}{l}\text { General } \\
\text { Musculoskeletal } \\
\text { (including spine) }\end{array}$ & & & 92 & \\
\hline Peripheral nerve & & & & \\
\hline
\end{tabular}

*including: carpal tunnel syndrome, cubital tunnel syndrome (elbow), De Quervein's syndrome

in sixth section. Specifically, as a result of muscle fatigue the shock absorbing capability is hampered, resulting in more impulsive loading and increasing the risk of overload injuries. Seventh section describes the phenomenon of repetitive strain injuries in upper string players, following abrupt and/or impulsive loading in either the right side as a result of intensive bow strokes, or the left side resulting from rapid fingering. The resemblance between upper string musicians and overhead athletes and industrial workers from the point of view of risk of injury and types of injuries is treated in In eighth section although musicians can be referred to as instrumental athletes, they are often deprived in terms of accessing onsite management of their musculoskeletal disorders. Finally, Appendix A presents the incidence of musculoskeletal disorders: incidence by site in the upper limb (Table A1), incidence by playing instrument (Table A2) and incidence within the string players (Table A2). A high incidence of musculoskeletal disorders in the upper limbs, particularly within the string instruments players is noted.

\section{Muscle-Tendon-Bone-Joint Interactions and Muscle Imbalance}

Muscles and tendons are responsible for the dynamic loading on joints

Muscles and bones act together in the human body. The bones provide the structural basis and support and the

Table A2. Incidence (\% of tested players) of pain and/or musculo-skeletal disorder by instrument

\begin{tabular}{|c|c|c|}
\hline & Fry ${ }^{39}$ & Lederman $^{64}$ \\
\hline violin & 75 & \multirow{4}{*}{$\begin{array}{l}89 \\
\text { (For Any } \\
\text { of the String } \\
\text { Instruments) }\end{array}$} \\
\hline Viola & 75 & \\
\hline Cello & 73 & \\
\hline Bass & 60 & \\
\hline Woodwinds & 69 & 52 \\
\hline Brass & 39 & \\
\hline Percussion & 32 & 63 \\
\hline
\end{tabular}

attached muscles provide, through their tendons, torques across the joints. At equilibrium, these torques act to stabilize the joints and under dynamic conditions they work as actuators for generating motion. Due to their short lever arms around the joint, the muscle/tendon forces responsible for exerting the torques are high. Thus, contracting muscles and their attached tendons are greatly responsible for the high-intensity loading on the bones and joints. ${ }^{18-20}$ Such a situation is encountered in the violinist's hand during playing, when the muscles, tendons, bones and joints are highly loaded. ${ }^{21}$ This is more emphasized during abrupt or impulsive playing such as playing tremolo, arpeggio etc., resulting in peak loads. ${ }^{15}$

\section{Muscle Imbalance}

Muscle imbalance occurs when muscles that surround the joint provide either lower or higher torque magnitudes than functionally required, thus resulting in the disruption of the joint function. A common example of pathological imbalance occurs when the neck flexors (such as glenohumeral) and scapular stabilizing muscles (such as scapulothoracic) become chronically weakened by fatigue due to extensive or repetitive activity. This evokes a compensatory action of tightening the pectoral, trapezius, sternocleidomastoid, and levator scapulae muscles. This type of muscle imbalance is known as Upper Crossed Syndrome. ${ }^{22-23}$ In musicians with PRMD, upper crossed syndrome was reported in the context of the postural stabilization system. ${ }^{24}$ Maintaining an unnatural posture for long periods of time not only can lead to discomfort and pain, but also to fatiguing of the muscles. To diagnose the upper crossed syndrome condition, tests were conducted to determine the muscles' strength and the flexion pattern of the head and neck. The tests also involved palpation of the upper trapezius for tightness and testing of the pectoral muscles for shortness. The reported results indicated a higher occurrence of the upper crossed syndrome in upper strings players compared to players of other instruments. Muscle imbalance induces in turn an altered body posture, consisting of a forward positioning of the head 


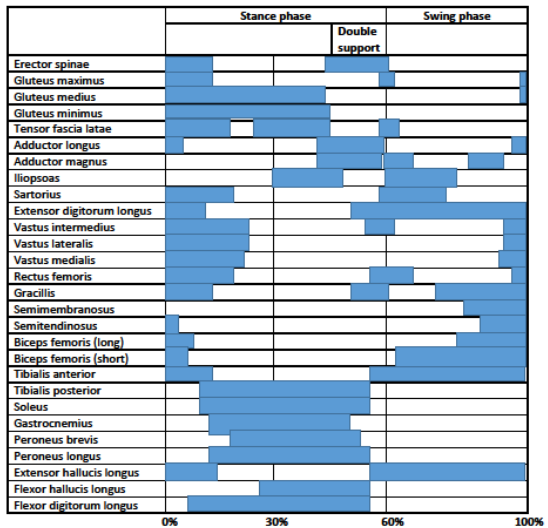

Figure 1a
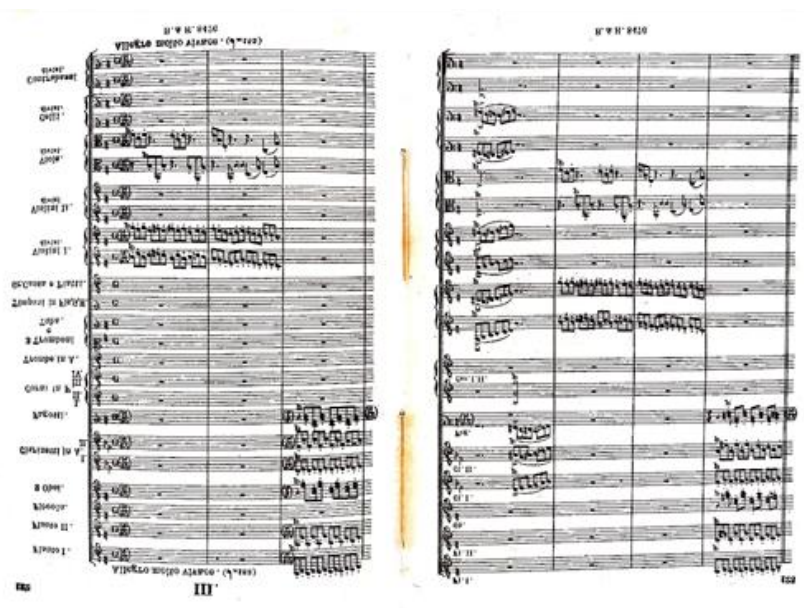

Figure 1b

Fig 1. Analogy between multi-muscle performance (1a) and multi-instrument symphonic score (1b). In both cases accurate control is required: central nervous system in walking and orchestra conductor in musical performance.

and an elevation and protraction of the shoulders. This alters the resting position of the scapula, changes the positional axis of the glenoid fossa and stimulates shoulder pain. ${ }^{24}$ Additionally, excessive stresses are applied to several regions, including the cervico-cranial junction, the cervico-cervical transition with the $\mathrm{C} 4$ and C5 spinal segments, and the T4 segment. ${ }^{22,25,26}$ Without treatment, it can break down the mechanics of the shoulder and deep arm movement patterns, leading to symptoms of inflammation of the tendons (tendonitis) and of the joint's bursa (bursitis), to rotator cuff injury as well as to functional impingement of the joint, the latter resulting from the compression of soft tissue structures between the humeral head and the undersurface of the acromion process and/or the coraco-acromial ligament.

\section{Measurement of Muscle Imbalance}

Surface electromyography (EMG) has been applied to study the patterns of muscle activation in playing different instruments, primarily as a means of understanding which groups of muscles are the most engaged during specific activities and hence may be at greatest risk for fatigue and pain. Such studies have generally focused on muscles of the upper trunk and the upper limb. ${ }^{9,27-28}$ In violinists, several research groups studied muscle imbalance by using quantitative EMG of the bilateral trapezius, deltoid, biceps, and triceps. EMG was compared between players with performance-related pain in the neck and shoulder region and those of asymptomatic violinists. ${ }^{29}$ The rectified EMG signal of the pain group was found to be significantly higher on the trapezius (highest), deltoid and biceps on the painful neck and shoulder. However, these results only provided indication of muscle activity but not of the actual level of fatigue and the perceived effort from the players. It was thus concluded that the pain group used significantly more force compared to the pain-free group. ${ }^{29-30}$

\section{Risks in increased deltoid activity}

The deltoid, as the prime abduction mover of arm, is in fact an antagonist muscle of the adduction pectoralis major and of the latissimus dorsi. Additionally, with elevating the arm the deltoid also elevates the humeral head. To counterbalance the resulting compression of the humeral head against the undersurface of the acromion and decrease the risk of injury of the supraspinatus tendon, a simultaneous contraction of the infraspinatus, teres minor and subscapularis rotator cuff muscles takes place. ${ }^{31}$ Thus, an increased deltoid activity will usually be followed by a decrease in subacromial space and an increased compression of the humeral head, increasing the risk of injuring the supraspinatus tendon.

\section{Significance of Subacromial impingement syndrome}

Subacromial Impingement Syndrome (SIS), the most common disorder of the shoulder, is a painful condition resulting from loss of subacromial space. ${ }^{32}$ SIS can be of two types: ${ }^{33}$ structural and functional. The first type is characterized by physical loss of area in the subacromial space due to inflammation (e.g. of the supraspinatus tendon) or to bony growth. In functional impingement, the relative loss of subacromial space is secondary to altered scapulohumeral mechanics resulting from glenohumeral instability and muscle imbalance. From the studies of Potau et al. ${ }^{34}$ and of Philipson et al, ${ }^{29}$ it appears that in upper strings players, a combination of these two types of impingement takes place.

\section{Neuro-muscular redundancy}

\section{Multi-muscle activity}

An interesting question in human activity is how many muscles are required for performing a given motor task? Not less intriguing is the question relating to the number of muscles actually engaged in this motor task. A trivial 
example is the rising of one's straight arm sideway to a horizontal position while standing still. Directly responsible for creating this motion are the deltoid, supraspinatus and upper trapezius with the accompanying extension of the pectorals (major and minor) and latissimus dorsi, all from the same side as the raised arm. It can be demonstrated, however, that the activities of other muscles are essential both for performing this task and for keeping the arm in the raised position and the body in equilibrium. From the contralateral side, these include the trapezius and other neck muscles, the erector spinae muscles and the gluteus medius and minimus muscles. From the same side as the elevated arm, the reaction force on the foot is increased and so is the activity in the muscles of the hip, thigh, calf, feet and toes. ${ }^{35,36}$ Thus, it is evident that in such a trivial body movement quite a number of muscles have to be involved from both sides of the body. Moreover, the additional involvement of muscles due to breathing and to the swaying motion of the body taking place during standing still should be accounted for. ${ }^{37}$ Another activity demonstrating the multitude of muscle involvement is human level walking, which is a dynamic activity of cyclic nature. Using electromyograms of the major muscles of the lower limb in locomotion have revealed the sequence of muscle activation and have shown that no less than 31 muscle groups are engaged in each leg during walking. ${ }^{18,38} \mathrm{~A}$ striking analogy between multimuscle performance and multi-instrument symphonic score is demonstrated in Figure 1. Figure 1a shows the sequence of muscle activation in a gait cycle, involving 28 of the muscle groups of the human lower limb. ${ }^{38}$ Figure $1 \mathrm{~b}$ shows two consecutive pages from the beginning of the third movement of Tschaikowky's symphony no.6 ("Pathetique"). Although 24 instrument lines can be counted, there are in fact more instruments because in some lines there are two roles like in the Oboes and Bassoons ( 2 of each). Like with the muscles, not all instruments are active all the time and in both cases accurate control is required: central nervous system in walking and orchestra conductor in musical performance.

\section{Muscles in violin playing}

In violin playing, the neck and shoulder muscles of the left side are engaged in holding the instrument. ${ }^{39}$ The sternocleidomastoid supports the violin during rotation and depression movement of the chin. ${ }^{30}$ The trapezius, while taking part in supporting and securing the violin, also holds the head in place, and acts as a stabilizer muscle for the continually abducted left arm. ${ }^{12,16}$ The left shoulder muscles, particularly the anterior deltoid, are used to support the raised left arm. ${ }^{40}$ The left biceps brachii is the principal muscle being used while playing as it facilitates and sustains supination and flexion of the elbow with its antagonistic triceps, the latter being active to stabilize and control the elbow in its partly extended position. In the forearm, the wrist and finger flexor and extensor muscles are used to control the fingering movements in the hand. With no significant extension movements occurring in the left arm, the triceps is primarily used for specific technical tasks such as vibrato, which is a quick repeated increase and decrease in the frequency of a played note. In a more specific way of studying vibrato playing, EMG was used to reveal the periodic pattern of the following muscles: the left biceps brachii, flexor digitorum, extensor digitorum, and pronator teres, came on and off in a periodic fashion, while the deltoid was constantly active. ${ }^{41}$ On the right side, the trapezius muscle is responsible for facilitating the bowing motion. ${ }^{16,40}$ The shoulder muscles, such as the deltoid, have been described as being active during the continual movement of the right arm when playing. The greatest muscle activity is found when the shoulder is horizontally abducted and flexed, at the beginning of a down-bow, especially at low speeds. ${ }^{2,13}$ The biceps muscle in the right arm is active in both the down and upbow movement, although it is more forceful during the up-bow (flexion of the elbow and shoulder) as it works against gravity during that motion. ${ }^{13}$ EMG analysis shows that the biceps works more in the elbow than in the shoulder movement. ${ }^{40}$ During the down-bow, the deltoid and biceps in the right arm act eccentrically because their torques have to perform work against gravity torque. In the forearm the flexors and extensors are used to control the bow. ${ }^{2,39,42}$ The spatial distributions of surface EMG of the right trapezius and right and left erector spinae muscles were monitored during bowing. ${ }^{15}$ The results showed that sliding the bow upward from the tip toward the tail results in a 50\% higher muscle activity of the trapezius muscle than a downward bow. An increasing trapezius activity was also observed as the string position became increasingly lateral, from the most medial string toward the most lateral one. It was also reported that the activity of the left and right erector spinae muscles was reduced by $20 \%$ in case a backrest support was used by the violin player. In this same study, ${ }^{15}$ the effect of the Detaché technique of playing notes with broad but separate bow strokes was also measured. Examples of orchestral Detachés can be heard in Beethoven $7^{\text {th }}$ Symphony, $2^{\text {nd }}$ movement (allegretto), or Mahler $1^{\text {st }}$ Symphony, $3^{\text {rd }}$ movement "frere Jacques" Afsharipour et al. ${ }^{15}$ found that playing Detaché tail (sliding the bow downward, from the tail toward the tip) causes higher activity of the right erector spinae compared to the left erector spinae to keep the player balanced. In performing Detaché tip (sliding the bow upward from the tip toward the tail), the lumbar activities of the left and right side are balanced. This was explained as follows: the erector spinae muscles assist in the control of bending forward at the waist as well as in returning to the erect position. During performing fast movements such as Detaché tail, the player rotates and somewhat bends toward his left. This movement, is likely to cause asymmetry in the activity of the lumbar muscles. In playing the Detaché tip no leaning toward the left is needed since the length of 
the bow compensate the required length to reach the string with the tip of the bow.

\section{Concentric vs eccentric muscle activity in Bowing}

In the elbow joint of the bowing arm, the transition from up-bow to down-bow, is performed through alternating the amount of activation of each of the biceps/triceps muscles. In the up-bow movement while the elbow is flexing, the higher biceps activity is concentric. It should be reminded that concentric terminology applies here because both the torque produced by the biceps and the elbow angular velocity are in the same direction. For changing to down-bow, while the elbow is in the course of extension, the triceps take over (here too, contracting concentrically). It has been shown that both antagonistic biceps and triceps muscles are active during up-bow and down-bow motions, with the biceps being dominant during up-bow and the triceps during down-bow. ${ }^{12,40}$ It should be noted, however, that the action of the nondominant muscle is eccentric: for instance, during downbow the biceps' torque and the elbow angular velocity are in opposite directions to each other (the biceps' role during down-bow is to control the motion of the elbow by somewhat braking its movement). Co-contraction of the elbow biceps and triceps muscles during the application of an elbow torque is illustrated in Figure 2 during down-bowing motion ${ }^{12,40}$ of the right arm. The required net elbow torque $\mathrm{T}$ determines the magnitude of the biceps $F_{1}$ and triceps $F_{2}$ forces to be applied as follows: $F_{1}=\left(T+F_{2} b\right) / a$, where $a$ and $b$ are the distances to the elbow joint of the biceps and triceps, respectively. It is noted that $\mathrm{F}_{1}$ strongly depends on the amount of coactivation of the antagonist triceps muscle $F_{2}$. This coactivation provides an example for the indeterminacy of the required muscle force, whose solution strongly depends on the amount of co-activation.

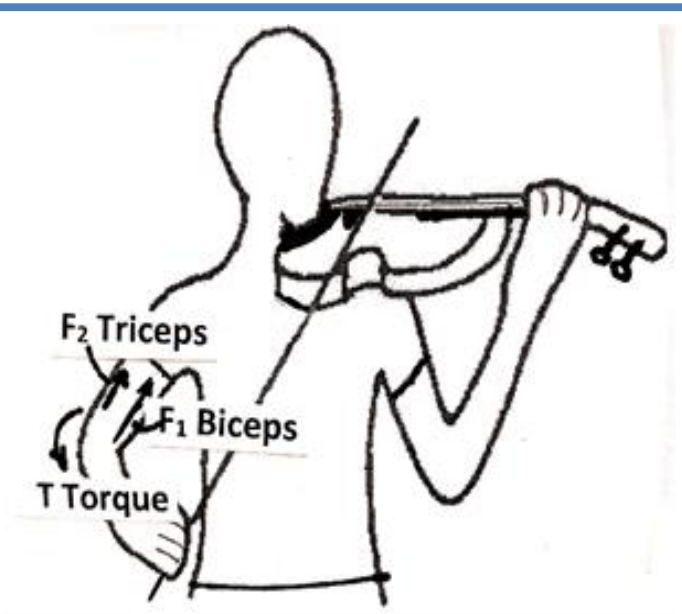

Fig 2. Co-contraction of the elbow biceps (Force $F_{1}$ ) and triceps (Force $F_{2}$ ) muscles during down-bowing motion of the right arm..$^{12,40}$

\section{Origin of redundancy}

The origin of the abovementioned neuro-muscular redundancy can be found in the descending pathways from the central nervous system to the peripheral nervous system. As a matter of fact, there exist multiple pathways for the performance of a given motor task such that a given central command may be executed in different ways and, conversely, the same end-result can be achieved from different trigger commands. ${ }^{43-45}$ A trivial example to illustrate the non-uniqueness of activation is how a joint torque of required intensity can be generated. ${ }^{46}$ Trivially, it can be produced by the contraction of one muscle only. However, the same required torque can also be produced by the summation of non-equal and opposing muscle forces from both sides of the joint. In this case, there will be an infinite number of ways to produce the same torque, involving the coactivation, or co-contraction, of antagonist muscles. ${ }^{47}$ From the purely mechanical aspect, such co-activation is undesirable because, despite the fact that the torque remains unchanged, it results in a higher net force in the joint. Nevertheless, co-activation is physiologically beneficial because it facilitates stability and controllability of posture and motion. Here are examples of co-activation in playing the upper strings instrument: in the left forearm, the wrist and finger flexor as well as extensor muscles are used to control the fingering movements in the hand. Similarly, in the right forearm both the flexors and extensors are used to control the bow. $2,12,39,42$

\section{Physiological benefits of redundancy}

Muscle redundancy involves more acting muscle groups than actually required and necessitates patterns of timings and intensities of those muscles, to be controlled by the central nervous system. It may be argued, though, that the involvement of all the participating muscles is not essential. It is probably this redundancy, however, that provides the smooth and graceful motion, both in walking and in playing. In the latter case, it allows to produce those specific and accurate movements, in both the hands and arms, which are essential to effectively achieve the proper tone, pitch, volume and quality of sound. ${ }^{40}$ It has been reported that upper string players tend to involve more effort with larger muscle groups than actually required. ${ }^{48}$ In playing, redundancy also refers to the multitude of ways in which a tone or a series of tones can be produced. From the purely biomechanical aspect, this refers to the specific muscles engaged in playing. It is also affected by the way the instrument is being held. ${ }^{16,49,50}$ Various playing techniques have been reported, opening to the player several different ways to play a given passage or circumvent a difficulty. ${ }^{51-53}$ However, in the course of learning and with increasing practice, one of those techniques is usually favored and adopted and an individual optimal efficiency can be achieved. $^{51,54}$ In general, redundancy of the neuro 
muscular system opens possibilities of exploring alternative ways of playing in cases injury comes about.

\section{Biomechanical Indeterminacy}

Indeterminacy occurs when the number of unknowns exceeds the number of available biomechanical equations (see later Section Biomechanical Model). Indeterminacy is associated with a multitude of possible solutions of the available system of equations and is due to the multitude of muscles, tendons and ligaments. Conventional methods of addressing mechanical indeterminacy usually refer to the implementation of optimization criteria, ${ }^{55}$ which provide supplementary equations intended to eliminate inadequate solutions. The level of indeterminacy is expected to decrease with the reduction of redundancy and more accurate solutions can be achieved. For instance, in cases of muscle deficiency or muscle paralysis the system's redundancy is reduced. ${ }^{56}$ At any event, information from electromyograms may become instrumental in resolving the musculo-skeletal system of equations muscle, by providing direct information about the muscle forces through their activities. $^{57}$

\section{Asymmetry in Posture and Function}

\section{Left and right sides do different things}

Postural and functional asymmetry in upper string instruments stems from the structure of the instrument and the way this instrument is being held and played. ${ }^{58}$ The workload is not distributed symmetrically between both sides. As described earlier, on the left side the hand performs fine motor movements and the lower arm and wrist display extreme postures, resulting in a higher load on the left arm. On the right side, the upper limb performs the bowing and the shoulder is in a sustained state of abduction and flexion focusing playing disorders in that site. ${ }^{10,59}$

\section{Consequences of Asymmetry}

The upper extremity is the most common site of injury with the left side reported to be the more affected. . $^{6,10,60,61}$ The combination of asymmetrical postures and repetitive movements is particularly stressful and was reported to contribute to common pattern of overuse injuries in muscle, tendon and nerve damage, such as medial or lateral epicondylitis, myofascial pain, and wrist tendonitis. ${ }^{4,10,58,62-64}$

\section{Neck, shoulder, chest and spine}

Usually, the weight of instrument is held partly by the upper chest and clavicle and partly by the hand. ${ }^{6,65}$ Holding the instrument more horizontally and more to the side than usual, will result in pressure on the first rib, compression of the brachial plexus and myofascial tension in the pectoral muscles, scalenes, upper trapezius and levator scapulae. Over time, the thoracic outlet syndrome (TOS) which causes shoulder and neck pain and numbness in the fingers may develop. ${ }^{65} \mathrm{~A}$ musician with TOS typically demonstrates vague paresthesias and pain in the medial forearm and hand. Symptoms are provoked with hyperabduction of the shoulder, abduction and extension of the shoulder, or downward traction when the shoulder internally rotated.$^{64}$ A posture of left rotation of the head and tilt of the neck increases the mechanical loading on the left-sided intervertebral facet joints and narrows the cervical neural foramen increasing the risk for cervical radiculopathy. In some cases, the violinist plays also with an elevated left shoulder, resulting in a scoliotic posture of the thoracic spine, combined with a preference to carry the weight of the body on the right foot. This in turn induces a downward shift of the left pelvis, and a scoliotic curvature of the lumbar spine. ${ }^{6}$ Also required from upper string players are extreme external shoulder rotation, arm elevation and constant maximum supination of the left forearm, which can lead to bursitis and tendonitis of the shoulder muscles. The consequent load on the tendons of the muscles adjacent to the shoulder can cause overuse injuries and, additionally, prolonged arm elevation can increase intramuscular pressure. ${ }^{66}$ Abnormal posture also alters the alignment of cervical vertebrae, and restricts the upper rib movement. Asymmetry is often the cause of respiratory problems, due to compression of the left lung and to limiting the upper rib excursion on that side.

\section{Elbow, wrist, hand and fingers}

Ulnar neuropathy (cubital tunnel syndrome) at the elbow is often seen in bowed upper string players because their left arm is in prolonged elbow flexion. In addition to the effort required by the proximal joints and fingers to grasp the instrument correctly, a considerable effort is required to hold down and release the strings, in order to rapidly move between the positions of the different notes. This effort is enhanced due to excessive internal rotation of the left arm, involves a change in wrist and elbow angles and is accompanied by movements up and down the neck of the instrument. ${ }^{6}$ High intensity force is also needed to lift the fingers from the string and keep them elevated. ${ }^{17,40}$ Often the left wrist is flexed as the fingers curl to apply pressure to the strings. This is the classic position to induce carpal tunnel syndrome and may promote flexor carpi ulnaris tendonitis and ulnar nerve entrapment at the elbow and wrist. ${ }^{67}$ The repetitive dynamic loading may lead to injury at the tendon sheaths, at the fingers as well as at the muscles that move them. ${ }^{68} \mathrm{~A}$ more detailed analysis of the tendon and joint loads will follow later.

\section{In the right side}

Here, while the bowing is carried out, the palm of the hand is in pronation. ${ }^{10}$ The sustained state of abduction and flexion of the right shoulder can result in rotator cuff tendonitis ${ }^{67}$ and high incidence of shoulder pain. ${ }^{6}$ In relation to this latter syndrome, ${ }^{16}$ found that during bowing the right upper arm was elevated by $30-90^{\circ}$ for as long as a fourth of a violinists working time. ${ }^{67}$ Players with forward head posture and poor axial extension may 
experience difficulty with prolonged bowing. In some playing techniques the bowing arm performs a sharp fullrange pronation of the forearm with extension of the elbow on down-stroke. This may develop myofascial tension on the pronator teres and compress the median nerve (resembling carpal tunnel syndrome) and evoke entrapment of the ulnar nerve. ${ }^{65}$

\section{EMG and Kinematics}

The coordination between muscle activity and kinematics of the limb is of great interest. In studies on 3-D motion analyses of the bowing arm of string musicians and including angles of shoulder, elbow and wrist joints, individual reproducibility and clear differences between players in repeated testing was reported. ${ }^{50,69}$ Kinematics measurements were combined with EMG of the trapezius and serratus muscles to compare between injured violinists with SIS and uninjured violinists. ${ }^{14}$ The results of that study indicated that in the SIS group, the trapezius activity was shorter in duration than in the uninjured group. Additionally, in the SIS group there was increased posterior scapular tilting and increased scapular upward rotation, both were longer in duration. There was also an increased scapular internal rotation. The glenohumeral joint had a reduced amplitude in flexion and an increased amplitude in external rotation compared to the uninjured musicians. The muscle recruitment pattern of the serratus anterior and the upper trapezius was found to be consistent with these kinematic variations.

\section{Forces in tendons and joints of the left hand index finger caused by string fingering}

\section{Finger-Fingerboard force}

The force values within the tendons and joints of the left hand fingers while pressing the strings against the fingerboard are of great interest because they reflect on the potential damage caused there due to prolonged and repetitive intensive playing. A force transducer was thus introduced to measure the force exerted by the finger against the fingerboard during playing of a tone at different tempi. ${ }^{70-71}$ In the process of pressing the string, two force phases were reported: the first is the exertion of a transient force against the tension of the string during the pressing-down motion until contact with the fingerboard is reached. The second phase is exertion of an additional force to secure clamping of the string onto the fingerboard in the required pitch position. The reported finger force values ranged from $4.5 \mathrm{~N}$ at tempi smaller than $2 \mathrm{~Hz}$ to $1.7 \mathrm{~N}$ at tempi exceeding $2 \mathrm{~Hz}$, with the highest force in the index finger. The finger force was reported to be lower at softer dynamic levels of the tone.

\section{Biomechanical Model}

To evaluate the effect of these forces on the hand's tendons and joints, we refer to a previously developed biomechanical 3-D dynamic model for the index finger. ${ }^{21}$ In this model, the index finger is controlled by seven muscles and the two interphalangeal joints, proximal
(PIP) and distal (DIP), are represented as hinge joints capable of flexion and extension only. The metacarpophalangeal joint (MP) is modeled as a saddle joint capable of both flexion-extension as well as abduction-adduction motions. The model combines the following: equations of motion, force constraint equations describing the anatomy of the interacting tendons, changing geometry during motion, and elasticity of the tendons, yielding altogether 8 equations with 14 unknowns for the tendon and joint forces ( 7 tendons plus $2+2+3=7$ joint components). To solve this indeterminate problem, a non-linear optimization approach based on minimization of the square of muscle stresses was used. It should be pointed that muscle stress is the most popular optimization criterion in musculo-skeletal biomechanics $^{72}$ and the reason for squaring the stress values is intended to accentuate differences between the different tendons taking part in the model-solution. ${ }^{73} \mathrm{~A}$ pinch force was introduced to serve as external input load on the index finger. This force included three phases: free flexing motion with no contact force, decelerating motion with increasing contact force, and full intensity pinch force without motion (chosen here to be of $1 \mathrm{~N}$ magnitude). The model solution was intended to predict the tendon forces needed to produce a specified motion and interaction with the environment and was validated by comparison with previously published EMG data. ${ }^{74}$

\section{Tendon and Joint Forces}

The model results indicated that the flexor digitorum profundus (FDP) force reached nearly $5 \mathrm{~N}$ at full pinch. The joint forces at the MP and PIP joints were at $\sim 8 \mathrm{~N}$ and the DIP was negligible. The opposing extensor digitorum communis (EC) force exhibited a noticeable peak at mid excursion, reflecting its braking effect of the compressing motion. Once the external pinch force took effect, this extensor force gradually decreased. The bands of the extensor mechanism participated in a manner similar to the long extensor, in moderating the flexion action. The extensor slip (ES) bore particularly large forces $(8 \mathrm{~N})$ originating mainly from the elasticity of the extensor mechanism itself. This large force is required due to the relatively small moment arm of the ES. The terminal extensor (TE) was also active, supporting the distal phalanx. The forces of the radial band (RB) and ulnar band (UB) acted symmetrically to maintain the extensor mechanism balanced.

The three intrinsic muscles remained silent during all phases of the motion. When increasing the model magnitude of the input pinch force to $6 \mathrm{~N}$ (six fold the previous one), the forces obtained were as follows: FDP reached $20 \mathrm{~N}$, the flexor digitorum superficialis (FDS) 8 $\mathrm{N}$ and the joint forces reached $25 \mathrm{~N}$ for both the PIP and MP joints. The DIP force was in this case noticeable, though much smaller, nearly at $9 \mathrm{~N}$. At $6 \mathrm{~N}$ pinching intensity the extensor digitorum communis EC peaked at $12 \mathrm{~N}$ and the intrinsic radial interosseous (RI) was clearly noticeable at $9 \mathrm{~N}$. 


\section{From joint forces to joint stresses}

The justification of integrating the two studies of Kinoshita et al. ${ }^{70}$ and Brook et al. ${ }^{21}$ comes from the following reasons: (a) comparable loading (or pinching) force $4.5 \mathrm{~N}$ in the former study, versus $1-6 \mathrm{~N}$ in the latter; (b) in both studies load application is divided into two phases including transient force followed by full force. Thus, the force of $4.5 \mathrm{~N}$ measured by Kinoshita et al. ${ }^{70}$ infers on the joint and tendon forces derived in the Brook et al. ${ }^{21}$ for the index finger. For comparison, the reported joint forces for piano playing were 10.9, 19.3 1and 31.6 $\mathrm{N}$ for the DIP, PIP and MP joints, respectively. ${ }^{75}$ These values were slightly larger than those of keyboard typing. Using data about surface areas of the finger joints, ${ }^{76}$ the above joint loads for violin playing yield average joint cartilage stresses of 190, 410 and $230 \mathrm{kPa}$ for the DIP, PIP and MP joints, respectively. For piano playing the reported average stresses were 226, 314 and $295 \mathrm{kPa}$ for the DIP, PIP and MP joints, respectively. Comparing these stresses with those of weight bearing joints, the average stress in the hip is around $1.8 \mathrm{MPa}$ (for a typical load of 3 body weights, roughly corresponding to standing on one leg) but the peak stress may locally reach up to $13.5 \mathrm{MPa}$ in the anterior aspect of the acetabulum. ${ }^{77}$ Thus, the DIP and PIP joints' cartilage of the index finger appears to be much less stressed than that of weightbearing joints. However, although osteoarthritis due to joint degeneration is not reported to be a common problem in upper strings players, there are instances of index DIP accumulated joint degeneration. ${ }^{78}$ This is because the left fingers are moved at very high speeds and in a repetitive manner, potentially placing them at risk for injury due to accumulated fatigue damage. . $^{3,5,39}$

\section{Shock Absorption and Muscle Fatigue}

Apart from their function as joint actuators, muscles and their attached tendons also act as active shock absorbers capable of attenuating impact and high-frequency loads. ${ }^{79}$ Muscle fatigue, however, was shown to hamper the muscles from effectively absorbing impact shocks and therefore protecting the skeleton and joints from damage. ${ }^{80-84}$ For instance, studies in the lower limb have shown that during running muscle fatigue provokes an increase in the strain rate in the tibia, rather than in the maximal strain ${ }^{79}$ suggesting that loading of the bones and joints becomes more impulsive as fatigue progresses. Fatigue can thus be considered to be a type of muscle deficiency that potentially endangers the skeleton and joints with the likely consequence of reduction of the smoothness of motion, which is essential for normal movement. Due to the stiffer nature of movement, higher-frequency dynamic components contribute to loading abruptness and to enhanced joint degeneration. ${ }^{7,85-87}$ Thus, in situations of fatigue or more generally muscle-tendon impairment, both force production and shock absorption, are hampered with the following consequences: (a) increased transmission of impulsive loads; (b) loading imbalance on the joints, resulting in increased bending stresses on the supporting bones; (c) altered kinematics; and (d) increased risk of overload injuries and of joint degeneration.

\section{Repetitive Strain Injury in Upper string players}

Repetitive strain injuries (RSI) occur in tissues in response to repetitive stresses over multiple cycles, when the body's ability to adapt is exceeded.$^{85}$ In upper bowed string instruments, playing often requires multiple rapid, repetitive, and forceful movements by many small hand muscles whose strengths are significantly lower than those of the larger muscles, thus placing intrinsic muscles at risk for injury. ${ }^{88,89}$

Thus, the muscles, nerves and tendons of the forearm, elbows, wrists, hands, neck and shoulders are at great risk. Factors influencing the incidence of RSI include: (a) type of repetitive activities and fatigue, e.g. continuously performing a long-time high-intensity activity; (b) poor posture and (c) exposure to abrupt changes in the tissue loading. .85

The short term effect of RSI is a sudden appearance of pain, such as muscle-tendon strain injury. ${ }^{90-92}$ Accumulated long-term damage is found in the joints and spine, ${ }^{93,94}$ including inflammatory disorders with muscletendon strain and spine diagnosis being the most common in violinists and violists. $778,86,90,95$ Examples of abrupt and/or impulsive loading in upper string playing may result from: (a) stressful activation of bow strokes, such as during, tremolo, détaché, Martelé and arpeggio, ${ }^{15}$ or (b) stressful activation of the left wrist and forearm muscles due to string fingering, such as during vibrato. ${ }^{7}$

\section{Stressful activation of bow strokes}

Sustained tremolo playing occurs when the bow is moved rapidly up and down, while the muscles of the neck, shoulder-girdle complex and the wrist flexors and extensors are practically held in a state of isometric contraction. These quick back and forth movements of the right wrist may last over prolonged periods of time (e.g., in beginning of Bruckner $9^{\text {th }}$ and Mahler $2^{\text {nd }}$ symphony; prelude to Wagner's Die Walkure; Nielsen $5^{\text {th }}$ symphony) and can contribute to overuse injury of the extensor carpi radialis and flexor carpi ulnaris muscletendon units.

Occasionally, the ulnar nerve can become compressed in the ulnar (Guyon's) canal, provoking pain. ${ }^{67}$

\section{Stressful activation of left wrist and forearm muscles}

Another example presents itself during passages requiring rapid changes over the four strings of the instrument (e.g. solo viola bows arpeggios back and forth near the bridge of the instrument, as in the second movement of Berlioz symphony Herold in Italy) may strain the right rotator cuff, deltoid, and pectoralis muscles. ${ }^{67}$

Ackermann and Adams mention left side abductor digiti minimus and dorsal interossei muscle strains as additional injury site of the player ${ }^{96}$. 


\section{Common types of $R S$ injuries}

More generally, common types of RS injuries of the upper extremities in string players include the following: ${ }^{64,97}$

(a) carpal tunnel syndrome (also called median nerve compression): a repetitive use injury of the wrist or finger movement that is associated with pressure on the nerves that run through the wrist. The carpal tunnel is a channel in the palm side of the wrist. The carpal tunnel surrounds the tendons used to bend the fingers and wrist; and also the median nerve which controls the thumb.

(b) tennis elbow (also called radial nerve entrapment) can happen by overuse of the arm, forearm, and hand muscles resulting in elbow pain, e.g. when the arm is frequently bent and extended.

(c) other repetitive use injuries, including tenosynovitis, bursitis, thoracic outlet syndrome and tendonitis are common in the neck and shoulders; in fact, these also make up a significant portion of the injuries seen in professional athletes.

\section{Analogy with Overhead Sports and Industrial Workers Injuries}

\section{Overhead Sports injuries}

Similarities between sportspeople and musicians have previously been acknowledged, with musicians being referred to as musical or instrumental athletes. ${ }^{86,98-100}$ Like with athletes, musicians can be trained about the risks of musculoskeletal disorders (MSD) and how to prevent, minimize, or manage these disorders. Both population groups begin their careers at a young age, and have to commit to daily intensive exercising and practicing. Both are typically competitive, requiring high-level skills and are often exposed to pain during their activity. However, while in athletes MSD's can be either of traumatic or non-traumatic types, in musicians they are usually of the overuse, non-traumatic, type. ${ }^{101}$ It is thus of interest to compare between upper string players and overhead athletes from the point of view of neuro-musculoskeletal activities and disorders. From the perspective of health support, the populations of musicians and athletes differ significantly. ${ }^{101,102}$ While the athletes benefit from ongoing support from the sports medicine discipline, orchestra musicians are often deprived in terms of accessing onsite management of their MSDs. ${ }^{103-107}$ The consequence may be delayed diagnosis and treatment of the musicians' MSD's, while denying the accompanying pain and discomfort. A typical example of injury in overhead athletes is related to the severe loading on the upper limb of tennis players in whom the impacts from each strike are associated with accumulated damage, the most frequent being tennis elbow. As mentioned earlier, the tennis elbow injury also known as radial nerve entrapment, is also common in upper strings players as a result of overuse of the arm, forearm, and hand muscles, e.g. when the arm is frequently bent and extended, resulting in elbow pain.
Another example in overhead athletes damage is due to imbalance between the eccentrically-activated external rotator cuff muscles and the concentrically-activated internal rotator cuff muscles which is a primary risk factor for glenohumeral joint pain and injuries. ${ }^{108}$ Athletes with shoulder pain have a decreased rotator cuff muscle strength and are more susceptible to rotator cuff tears and labrum lesions. ${ }^{109}$ This imbalance can progress to either tissue damage and pain or to altered movement pattern. ${ }^{23,33}$ Subacromial impingement syndrome of the shoulder is the most common and painful disorder in overhead athletes ${ }^{32}$ and usually results from multiple factors including, among others nonphysiologic glenohumeral and scapular motion and altered kinematics of the head of the humerus. ${ }^{31}$ As shown earlier, upper string players are also at increased risk for shoulder impingement in the bowing arm. ${ }^{14}$ The muscle imbalance found in musicians in the posture stabilization system was reported to contribute to the SIS. ${ }^{24}$ In both athletes and upper string players a combination of structural and functional types of subacromial impingement syndrome takes place. ${ }^{29,32-34}$ Fatigue of the rotator cuff muscles, particularly in the infraspinatus, and teres minor muscles affects the scapular resting position and scapular kinematics as well as external rotation and stabilization functions of the shoulder. ${ }^{110-111}$ Changes in scapular kinematics may affect the amount of contact area in the subacromial space and facilitate impingement. ${ }^{112-114}$ Likewise, in the upper strings players impingement is accompanied by altered kinematics in the scapula and glenohumeral joint and in the activation pattern of the serratus anterior and the upper trapezius muscles. ${ }^{14,115}$

\section{Industrial vocations}

Chronic upper limb pain may also result from working occupation, involving tasks of repetitive nature. Despite the variety of tasks, similar predispositions to MSDs may develop in this group of workers in characteristic sites of the upper limb. Some examples are found from within the following areas: food production, construction, shop assistance and the like. ${ }^{116-119}$ The types of injury encountered here include fibrositis, rotator cuff syndrome, rheumatoid arthritis, cervical referred pain (cervical radiculopathy), lateral epicondylitis (tennis elbow), de Quervain's tenosynovitis and carpal tunnel syndrome. ${ }^{120}$ For instance, meatcutters were reported to have about $9 \%$ prevalence of epicondylitis and $4.5 \%$ of tenosynovitis. The risk increased with age and number of exposure years. ${ }^{121}$ Another disorder is the relatively high prevalence of tenosynovitis and humeral tendinitis in assembly-line packers. ${ }^{119}$ For comparison, in the upper strings players often the left wrist is flexed as the fingers curl to apply pressure to the strings. This is the classic position to induce carpal tunnel syndrome and may promote flexor carpi ulnaris tendonitis and ulnar nerve entrapment at the elbow and wrist. ${ }^{67}$ Other similar overuse injuries in upper strings include neurologic 
entrapment neuropathies, anoxia (venous congestions), traction on neural tissue (due to awkward playing posture and to friction), carpal tunnel syndrome (compression of digital nerves from gripping bow tightly), ulnar neuropathies in violinists (constant flexion of left elbow, more common), radial neuropathies (tennis elbow, due to post interosseous branch of radial nerve becoming entrapped, though it is less common, ${ }^{122}$ thoracic outlet syndrome; ulnar neuropathy at elbow; carpal tunnel; cervical radiculopathy. ${ }^{58,123}$

\section{Summary}

A combination of factors exposes string musicians to neuro-musculo-skeletal disorders associated with pain and damage. These include: overuse due to the long playing hours involving repetitive movements under stressful conditions in unnatural posture. Although the disorders are usually non-traumatic, they may often lead to prolonged or even permanent damage. These include bursitis and tendinopathies of the shoulder muscles, rotator cuff tendonitis, injury at the tendon sheaths, medial or lateral epicondylitis (or tennis elbow), myofascial pain, and wrist tendonitis (and/or carpal tunnel syndrome, De Quervein's syndrome). In cases of intensive performance, a traumatic injury may result, requiring drastic means of intervention. This review provides a description and interpretation of the playingrelated motor disorders in performing musicians, specifically violinists and upper strings players. It should be reminded that a large variety of methodologies (as summarized in Table 1) was implemented to describe these motor disorders.

These methodologies have included kinematic, dynamic, electromyographic measurements and modeling. Additionally, non-engineering methods including physical examination, visual assessment and quantitative questionnaire have been used.
The playing related motor disorders are further interpreted by means of biomechanical concepts, including asymmetry and imbalance in the musculoskeletal system; muscle-bone-joint interactions in imbalance; static and repetitive overloading; effects of fatiguing and of selective muscle fatiguing on kinematics and neuro-muscular redundancy. This approach should provide foundations for further improving devices and techniques aimed at reducing damage associated with prolonged playing.

\section{Appendix A: Incidence of musculo-skeletal disorders}

\section{A1. Incidence by site in the upper limb}

Numerous studies on the incidence of musculo-skeletal disorders which lead to pain and/or injury in orchestra musicians have been published. It should be mentioned that most musicians' disorders are of the overuse type, i.e., non-traumatic. A comparative summary of the results of some of these studies by the site in the upper limb is presented in Table A1. Under the general definition of musculoskeletal injuries, including spine disorders, the high incidence of 89 percent of the population of players is particularly noticeable. ${ }^{64}$ The distribution among the other sites reveals a large variability among the various report, from 9 to 63 percent. $^{39,116,124}$

\section{A2. Incidence by playing instrument}

The incidence of playing disorders by instruments within the orchestra is displayed in Table A2 for some published reports. It should be noted that the large variability seen both in Tables A1 and A2 is due to the size and type of the population of players studied in the different studies (professionals or non-professionals players, age, gender, etc).

A3. Incidence within string players

Table 1 Methodologies used to diagnose playing-related musculo-skeletal disorders

\begin{tabular}{|l|l|l|}
\hline Method & Description & References \\
\hline Electrogoniometers & $\begin{array}{l}\text { Postural changes (pronation supination; radial ulnar } \\
\text { deviation }\end{array}$ & 10 \\
\hline Electromyography & $\begin{array}{l}\text { Surface EMG of muscles such as trapezius etc; EMG } \\
\text { spatial distribution; Muscle imbalance } \\
\text { Force assessment; Postural issues }\end{array}$ & $\begin{array}{l}9,12,13,15,16,27,28, \\
29,41 \\
30\end{array}$ \\
\hline 3-D Kinematics + EMG & $\begin{array}{l}\text { EMG analysis using the exposure variation analysis } \\
\text { (EVA) }\end{array}$ & $12,13,14,40,50,69$ \\
\hline $\begin{array}{l}\text { 3-D Kinematics + Forceplates + } \\
\text { EMG }\end{array}$ & $\begin{array}{l}\text { Changes in musculo-kinematic configuration and } \\
\text { muscle activity during playing }\end{array}$ & 51 \\
\hline $\begin{array}{l}\text { Physical examination; visual } \\
\text { qssessment and quantitative } \\
\text { questionnaire }\end{array}$ & $\begin{array}{l}\text { For muscle strength, tightness etc... } \\
\text { Task-specific scale about performance-related } \\
\text { musculo-skeletal disorders and qualitative posture } \\
\text { assessment }\end{array}$ & $1,6,17$ \\
\hline Force transducer & Finger-fingerboard force & 70,71 \\
\hline Modeling & $\begin{array}{l}\text { Dynamic model for index finger to reveal muscle and } \\
\text { joint forces }\end{array}$ & 21 \\
\hline
\end{tabular}


Among the various orchestra players, the string players (violin, viola, cello and bass) have the highest incidence (89 percent, Table A2) of pain and/or musculo-skeletal disorder. ${ }^{64}$ Particularly, the upper string players have been identified as the most affected group of instrumentalists and the most vulnerable to playing related musculo-skeletal disorders, leading to pain and injury. Thus, the upper body and upper extremities are the most common sites of injury of violin and viola players.

\section{List of acronyms}

EMG - electromyography

DIP - distal interphalangeal joint

EC - extensor digitorum communis

ES - extensor slip

FDP - flexor digitorum profundus

FDS - flexor digitorum superficialis

MP - metacarpophalangeal joint

PIP - proximal interphalangeal joint

PRMD - playing related musculo-skeletal disorders

$\mathrm{RB}$ - radial band

RI - radial interosseous

RSI - repetitive strain injuries

SIS - subacromial impingement syndrome

TE - terminal extensor

TOS - thoracic outlet syndrome

UB - ulnar band

\section{Authors contributions}

Joseph Mizrahi is the sole author.

\section{Acknowledgments}

None.

\section{Funding}

This research received no external funding.

\section{Conflict of Interest}

The author declares no conflict of interest..

\section{Ethical Publication Statement}

We confirm that we have read the Journal's position on issues involved in ethical publication and affirm that this report is consistent with those guidelines.

\section{Corresponding Author}

Professor Joseph Mizrahi, Department of Biomedical Engineering, Technion, Israel Institute of Technology, Haifa 32000, Israel

ORCID iD: 0000-0002-2582-6269

E-mail: jm@bm.technion.ac.il

\section{References}

1. Caldron PH, Calabrese LH, Clough, JD, Lederman RJ, Williams G, Leatherman J. A survey of musculoskeletal problems encountered in high level musicians. Med Probl Perform Art 1986;1:136-9.
2. Lockwood AH. Medical problems in secondary school-aged musicians. Med Probl Perform Art 1988;3:129-32.

3. Manchester RA. The incidence of hand problems in music students. Med Probl Perform Art 1988;3:158.

4. Larsson LG, Baum J, Mudholkar GS, Kollia, GD. Benefits and disadvantages of joint hypermobility among musicians. N Engl J Med 1993;329:107982. doi: 10.1056/NEJM199310073291504

5. Fishbein M, Middlestadt SE, Ottati V, Straus S, Ellis A. Medical problems among ICOSM musicians: overview of a national survey. Med Probl Perform Art 1988;3:1-8.

6. Hohls QR. An investigation into performance related musculoskeletal disorders of professional orchestral string musicians in South Africa. Dissertation submitted in partial compliance with the requirements for the Master's Degree in Technology at the Durban University of Technology, January 2010.

7. Lee HS, Park HY, Yoon JO, et al.. Musicians' medicine: musculoskeletal problems in string players. Clin Orthop Surg 2013;5:155-60, doi: 10.4055/cios.2013.5.3.155

8. Gembris H. Heye A, Seifert A. Health problems of orchestral musicians from a life-span perspective: Results of a large-scale study. Music \& Science 2018;1:1-20. doi: 10.1177/2059204317739801

9. Kelleher LK, Campbell KR, Dickey JP. Biomechanical Research on Bowed String Musicians. A Scoping Study. Performing Arts Medicine Association Symposium, Snowmass, CO, July 19-23, 2013. pp 212-8. doi: 10.21091/mppa. 2013.4042

10. Handal C. Documenting postural changes and repetition among violin players and their influence in the development of musculoskeletal disorders. LSU Master's Theses, Louisiana State University and Agricultural and Mechanical College; 2013. p 62.

11. Brown S. Shoulder pain and the instrumental musician. J Back Musculoskelet Rehabil 1992;2:16-27. doi: 10.3233/BMR-1992-2204

12. Wales J. 3D Movement and Muscle Activity Patterns in a Violin Bowing Task, M.Sc. Applied Health Sciences, Brock University; 2007.

13. Shan G, Visentin P, Schultz A. Multidimensional signal analysis as a means of better understanding factors associated with repetitive use in violin performance. Med Prob Perf Art 2004;19:129-39.

14. Reynolds JF. Shoulder Joint and Muscle Exposure in Violin Musicians: A Three-Dimensional Kinematic and Electromyographic Exposure Variation Analysis. A dissertation submitted to the faculty of the Graduate School and of the University of Minnesota, May 2009. 
15. Afsharipour B, Petracca F, Gasparini M, Merletti R. Spatial distribution of surface EMG on trapezius and lumbar muscles of violin and cello players in single note playing. J Electromyogr Kinesiol 2016;31:144-53. doi: 10.1016/j.jelekin.2016.10. 003

16. Fjellman-Wiklund A, Grip H, Karlsson JS, Sundelin, G. EMG trapezius muscle activity pattern in string players: Part I-Is there variability in the playing technique? Int J Ind Ergon 2004;33:347-56. Doi: $10.20697 / j a s j .72 .12 \_783$

17. Vesamäki E. Surviving Over-practice Injury, The quest to find freedom in violin technique, Thesis for the degree of Master, Royal College of Music in Stockholm, Department of Classical Music, 2015, p.38.

18. Mizrahi J. Muscle/Bone Interactions in the Musculo-Skeletal System. Published by the Center of Excellence for Applied Biomedical Modelling and Diagnostics, Warsaw (ISSN 1733-0874); 2004

19. Martin RB, Burr DB. Structure, Function and Adaptation of Compact Bone. New York; Raven Press; 1989.

20. Nordin M, Frankel V. (1989). Biomechanics of Bone. In: Nordin M, Frankel V eds. Basic Biomechanics of the Musculoskeletal System. Philadelphia (PA): Lea and Febiger, pp 3-29.

21. Brook N, Mizrahi J, Shoham M, Dayan J. A biomechanical model of index finger dynamics. Med Eng Phys 1995; 17:54-63.

22. Janda V. Proximal crossed syndrome. In: Hutson M, Ellis R, eds. Textbook of musculoskeletal medicine. 1st ed. New York: Oxford University Press; 2006. pp 48-9.

23. Page P, Frank CC, Lardner R. Assessment and Treatment of Muscle Imbalance, The Janda Approach; Human Kinetic Publishers; 1988. ISBN 9781450408288.

24. Steinmetz A, Seidel W, Muche B. Impairment of postural stabilization systems in musicians with playing-related musculoskeletal disorders. J Manipulative Physiol Ther 2010;33:603-11. doi: 10.1016/j.jmpt.2010.08.006

25. O'Shea C, Bettany-Saltikov JA, Warren JG. Effect of same-sided and cross-body load carriage on 3D backshape in young adults. Stud Health Technol Inform 2006;123:159-63.

26. Jager M, Luttmann A. The load on the lumbar spine during asymmetrical bi-manual materials handling. Ergonomics 1992;35:783-805. Doi 10.1080/0014 0139208967363

27. Kjelland JM. Application of electromyography and electromyographic biofeedback in music performance research: a review of the literature since 1985. Med Probl Perform Art 2000;15:115-8.

28. Kok LM, Vliet Vlieland TPM, Fiocco M, Nelissen RGHH. A comparative study on the prevalence of musculoskeletal complaints among musicians and non-musicians. $B M C$ Musculoskelet Disord 2013;14:1-7.

http://www.biomedcentral.com/1471-2474/14/9

29. Philipson L, Sorbye R, Larsson P, Kaladjev S. Muscular load levels in performing musicians as monitored by quantitative electromyography. Med Probl Perform Art 1990;5:79-82.

30. Levy CE, Lee WA, Brandfonbrener AG, et al. Electromyographic analysis of muscular activity in the upper extremity generated by supporting a violin with and without a shoulder rest. Med Probl Perform Art 1992;7:103-9.

31. Payne LZ, Deng XH, Craig EV, et al.. The combined dynamic and static contributions to subacromial impingement, a biomechanical analysis. Am J Sport Med 1997;25:801-8. doi: 10.1177/036354659702500612

32. Michener LA, McClure PW, Karduna AR. Anatomical and biomechanical mechanisms of subacromial impingement syndrome. Clin Biomech 2003;18:369-79. doi: 10.1016/S0268-0033(03)000 47-0

33. Page, P. Shoulder muscle imbalance and subacromial impingement syndrome in overhead athletes. Int J Sports Phys Ther 2011;6: 51-8.

34. Potau JM, Bardina X, Ciurana N, et al. Quantitative analysis of the deltoid and rotator cuff muscles in humans and great apes. Int J Primatol 2009;30:697708.

35. Juhan D. Job's Body : A Handbook for Bodywork. Barrytown: Station Hill Press. 2003.

36. Benedetti E. Cello, bow and you: putting it all Together. Oxford: Oxford University Press; 2017.

37. Mizrahi J, Susak Z. Bilateral reactive force patterns in postural sway activity of normal subjects. Biol Cybern 1989;60:297-305.

38. Bechtol CO. Normal Human Gait. In: Bowker JH, Hall CB, eds. Atlas of Orthotics. St. Louis; Mosby; 1975. pp 133-43.

39. Fry HJH. Incidence of overuse syndrome in the symphony orchestra. Med Probl Perform Art 1986;1:51-5.

40. Szende O, Nemessuri M. The physiology of violin playing. Budapest: Collet's Ltd, Akademiai Kiado; 1971.

41. Bejjani FJ, Ferrara L, Pavlidis L. A comparative electromyographic and acoustic analysis of violin vibrato in healthy professional violinists. Med Probl Perform Art 1989;4:168-75.

42. Bejjani FJ, Kaye GM, Benham M. Musculoskeletal and neuromuscular conditions of instrumental musicians. Arch Phys Med Rehabil 1996;77:40613. doi: 10.1016/S0003-9993(96)90093-3

43. Bernstein $\mathrm{N}$. The coordination and regulation of movement. London; Pergamon Press; 1967.

44. Shumway-Cook A, Woollacott M. Motor Control: Theory and Practical Applications, Baltimore, MD; Williams \& Wilkins; 1995. 
45. Mizrahi J. Mechanical impedance and its relations to motor control, limb dynamics, and motion biomechanics, J Med Biol Eng 2015;35:1-20, DOI 10.1007/s40846-015-0016-9.

46. Mizrahi J, Daily D. Modeling the foot-strike event in running fatigue via mechanical impedances. In: Tarum Goswani $\mathrm{T}$ ed. Injury and Skeletal Biomechanics. InTech, (ISBN 978-953-51-06906); 2012. pp 153-170.

47. Katz A, Tirosh E, Marmur R, Mizrahi J. Enhancement of muscle activity by electrical stimulation in cerebral palsy - a case control study. J Child Neurology 2008;23:259-67. doi: 10. 1177/0883073807308695

48. Moore M, DeHaan L, Ehrenberg T, Gross L, Magembe C. Clinical assessment of shoulder impingement factors in violin and viola players. Med Probl Perform Art 2008;23:155-63.

49. Berque P. Gray H. The influence of neck-shoulder pain on trapezius muscle activity among professional violin and viola players: an electromyographic study. Med Prob Perf Art 2002;17:68-75.

50. Tulchinsky E, Riolo L. A biomechanical motion analysis of the violinist's bow arm. Med Probl Perform Art 1994;9:125-30.

51. Loram A. A Scientific investigation into violin and viola playing. MSc in Performing Arts Medicine, University College London, Division of Surgery and Interventional Science. 2013.

52. Hoppmann RA.. Musculoskeletal problems of instrumental musicians. In: Sataloff $\mathrm{R} T$, Brandfonbrenner AG, Lederman RJ. eds. Performing Arts Medicine, 3rd ed. Narberth, PA: Science and Medicine Art Publishers; 2010. p 207.

53. Wynn Parry CB. The interface. In: Wynn Parry, $\mathrm{CB}$, Winspur I, eds. The musician's hand. London, Martin Dunitz Ltd; 1998.

54. Tubiana R. Movements of the fingers. Med Probl Perform Art 1988;3:123-8.

55. Patriarco AG, Mann RW, Simon SR, Mansour JM. An evaluation of the approaches of optimization models in the prediction of muscle forces during human gait. J Biomech 1981;14:513-25. doi: 10.1016/0021-9290(81)90001-4

56. Suponitsky Y, Verbitsky O, Peled E, Mizrahi J. Effect of selective fatiguing of the shank muscles on single-leg standing sway. J Electromyogr Kinesiol 2008;18:682-9. doi: 10.1016/j.jelekin.2007.01.009

57. Vaughan CL, Davis BL, O'Connor JC. Dynamics of Human Gait. Champaign; Human Kinetic Publishers; 1992.

58. Dommerholt J. Performing arts medicine Instrumentalist musicians, Part II - Examination. J Bodyw Mov Ther 2010;14:65-72. doi: 10.1016/j. jbmt.2009.02.004

59. Kok LM, Groenewegen KA, Huisstede BMA, et al. The high prevalence of playing-related musculoskeletal disorders (PRMDs) and its associated factors in amateur musicians playing in student orchestras: A crosssectional study. PLoS ONE 2018;13: e0191772. doi: 10.1371/ journal.pone.0191772

60. Burkholder KR, Brandfonbrener AG. PerformanceRelated Injuries among Student Musicians at a Specialty Clinic. Med Probl Perform Art 2004:19:116-22.

61. Miller G, Peck F, Watson JS. Pain disorders and variations in upper limb morphology in music students. Med Probl Perform Art 2002;17:169-72.

62. Feuerstein M, Hickey PF. Handbook of pain assessment, Ergonomic approaches in the clinical assessment of occupational musculoskeletal disorders, New York; Guilford Press; 1992.

63. Kuorinka I, Forcier L. Work-Related Musculoskeletal Disorders: A Reference Book for Prevention. London: Taylor \& Francis; 1995. ISBN 0-7484-0132-6

64. Lederman RJ. Neuromuscular and musculoskeletal problems in instrumental musicians. Muscle Nerve 2003;27:549-61. doi: 10.1002/mus. 10380

65. Colley E. Injury in the Orchestra: The Ergonomic Nightmare. In: Robertson SA ed. Contemporary ergonomics 1994. Proceedings of the Ergonomics Society's Annual Conference, University of Warwick 19-22 April 1994, University College, London; Taylor and Francis; 1994. pp 22-6.

66. Moraes GFS, Antunes AP. Musculoskeletal disorders in professional violinists and violists. Systematic review. Acta Ortop Bras 2012;20:43-7. doi: 10.1590/S1413-78522012000100009

67. Chong J, Lynden M, Harvey D, Peebles M. Occupational Health Problems of Musicians. Can Fam Physician 1989;35:2341-8.

68. Moore A, Wells R, Ranney D. Quantifying exposure in occupational manual tasks with cumulative trauma disorder potential. Ergonomics 1991;34:1433-53. Doi: 10.1080/00140139108964 888

69. Turner-Stokes L, Reid K. Three-dimensional motion analysis of upper limb movement in the bowing arm of string-playing musicians. Clin Biomech 1999;14:426-33.

70. Kinoshita H, Obata S. Left hand finger force in violin playing: Tempo, loudness, and finger differences. J Acoust Soc Am 2009;126:388-395. doi: 10.1121/1.3139908

71. Grosshauser T, Troster G. Finger position and pressure sensing techniques for strings and keyboard instruments, 13th International Conference on New Interfaces for Musical Expression (NIME'13), May 27 - 30, KAIST, Daejeon, Korea;2013.

72. Zajac F, Winters JM. Modeling musculoskeletal movement systems: joint and body-segment dynamics, musculotendinous actuation, and 
neuromuscular control. In: Winters JM, Woo SL-Y, eds. Multiple Muscle Systems-Biomechanics and Movement Organization. New York; SpringerVerlag; 1990

73. Buchner HJ, Hines MJ, Hemami H. A dynamic model for interphalangeal coordination. J Biomech 1988;21:459-69. doi: 0.1016/0021-9290(88)902382

74. Long C, Conrad PW, Hall EA, Furler, SL. Intrinsicextrinsic muscle control of the hand in power grip and precision handling. $\mathrm{J}$ Bone Joint Surg 1970;52A:853-67.

75. Butz KD, Merrell G, Nauman EA. A biomechanical analysis of finger joint forces and stresses developed during common daily activities. Comput Methods Biomech Biomed Eng 2012;15:131-40. Doi: 10.1080/10255842.2010.517525

76. Moran JM, Hemann JH, Greenwald AS. Finger joint contact areas and pressures. J Orthop Res 1985;3:49-55. doi: 10.1002/jor.1100030106

77. Mizrahi J, Solomon L, Kaufman B, Duggan TO'D. An experimental method for investigation of the distribution of loading forces in the human cadaver hip joint. J Bone Joint Surg 1981;63B:610-3.

78. Schwartz DA, Peimer CA. Distal interphalangeal joint implant arthroplasty in a musician. J Hand Ther 1998;11:49-52. doi: 10.1016/S0894-1130(98) 80061-6

79. Mizrahi J, Verbitsky O, Isakov E. Fatigue-related loading imbalance on the shank in running: a possible factor in stress fractures. Annals Biomed Eng 2000;28:463-9.

80. Beck BR. Tibial stress injuries. An aetiological review for the purposes of guiding management. Sports Med 1998;26:265-79.

81. Burr DB, Martin RB, Schaffler MB, Radin EL. Bone remodeling in response to in vivo fatigue microdamage. J Biomech 1985;18:189-200.

82. Milgrom C. The Israeli elite infantry recruit: a model for understanding the biomechanics of stress fractures. J R Coll Surg Edinburgh 1989;34:S18S21.

83. Schaffler MB, Radin EL, Burr DB. Long-term fatigue behavior of compact bone at low strain magnitude and rate. Bone (N.Y.) 1990;11:321-6. doi: 10.1016/8756-3282(90)90087-F

84. Radin EL. Role of muscles in protecting athletes from injury. Acta Med Scand Suppl 1986;711:1437. doi: 10.1111/j.0954-6820.1986.tb08943.x

85. Burr DB. Bone, exercise and stress fracture. In: Holloszy JO, ed. Exercise and sport sciences review. Baltimore, MD; Williams and Wilkins; 1997. pp. 171-94.

86. Quarrier N. Performing arts medicine: The musical athlete. J Orthop Sports Phys Ther 1993;17:90-5. doi: 10.2519/jospt.1993.17.2.90
87. Radin EL, Parker HG, Pugh GV, et al. Response of joints to impact loading. J Biomech 1973;6:51-7. doi:10.1016/0021-9290(73)90037-7

88. Dawson WJ. Intrinsic muscle strain in the Instrumentalist. Med Probl Perform Art 2005;20:66 $-9$.

89. Manchester RA, Flieder D. Further observations on the epidemiology of hand injuries in music students. Med Probl Perform Art 1991;6:11-4.

90. Dawson WJ. Upper-extremity problems caused by playing specific instruments. Med Probl Perform Art 2002;17:135.

91. Feinberg J, Brandt KD, Steichen JB. Tenodesis of the digital extensors in a violist: The unmasking of a congenital anomaly by technical proficiency. Med Probl Perform Art 1988;3:109-12.

92. Patrone NA, Hoppman RA, Whaley Y, Schmidt R. Digital nerve compression in a violinist with benign hypermobility: a case study. Med Probl Perform Art 1989;4:91-4.

93. Radin EL, Paul IL, Rose RM. Mechanical factors in etiology of osteoarthrosis. Ann Rheum Dis 1975;34:132-3.

94. Wosk J, Voloshin AS. Wave attenuation in the skeletons of young healthy persons. J Biomech 1981;14:261-8. doi: 10.1016/0021-9290(81)900713

95. Barczyk-Pawelec K, Sipko T, DemczukWłodarczyk E, Boczar A. Anteroposterior spinal curvatures and magnitude of asymmetry in the trunk in musicians playing the violin compared with nonmusicians. J Manipulative Physiol Ther 2012;35:319-26. doi: 10.1016/j.jmpt.2012.04.013

96. Ackermann B, Adams R. Physical characteristics and pain patterns of skilled violinists. Med Probl Perform Artists 2003;18:65-71.

97. Kaufman-Cohen Y, Ratzon NZ. Correlation between risk factors and musculoskeletal disorders among classical musicians. Occup Med 2011; 61:90-95. doi: 10.1093/occmed/kqq196

98. Ackermann B, Driscoll, T. Assessing performancerelated shoulder pain in the musical athlete - Are typical shoulder examinations enough? Med Sci Sports Exerc 2013;45:65.

99. Moran C. Using myofascial techniques to treat musicians. J Hand Ther 1992;5:97-101.

100. Schaefer P, Speier J. Common medical problems of instrumental athletes. Curr Sports Med Rep 2012;11:316-22. doi: 10.1249/JSR.0b013e318272 c8ae

101. Stanhope J. Physical performance and musculoskeletal disorders: Are musicians and sportspeople on a level playing field? Performance Enhancement \& Health 2016;4:18-26. doi: 10. 1016/j.peh.2015.11.004

102. Dick R, Berning J, Dawson W, et al. Athletes and the arts - The role of sports medicine in the performing arts. Curr Sports Med Rep 
2013;12:397-403. doi: 10.1249/JSR.0000000000 000009

103. Ackermann B, Kenny D. Fortune J. Incidence of injury and attitudes to injury management in skilled flute players. Work, 2011;40:255-9. DOI: 10.3233/WOR-2011-1227

104. Ioannou C, Altenmüller E. Approaches to and treatment strategies for playing-related pain problems among Czech instrumental music students. An epidemiological study. Med Probl Perform Art 2015;30:135-142.

105. Kreutz G, Ginsborg J, Williamon, A. Healthpromoting behaviours in conservatoire students. Psychol Music 2009;37:47-60. doi:10.1177/03057 35607086047

106. Stanhope J, Milanese S, Grimmer K. University woodwind students' experiences with playingrelated injuries and their management: A pilot study. J Pain Res 2014;7:133-48.

107. Wood G. Prevalence, risk factors, and effects of performance-related medical disorders (PRMD) among tertiary-trained jazz pianists in Australia and the United States. Med Probl Perform Art 2014;29:37-45.

108. Niederbracht Y, Shim AL, Sloniger MA, et al. Effect of a shoulder injury prevention strength training program on eccentric external rotator muscle strength and glenohumeral joint imbalance in female overhead activity athletes. J Strength Cond Res 2008;22:140-5. doi: 10.1519/JSC. 0b013e31815f5634

109. Mihata T, Gates J, McGarry MH et al. Effect of rotator cuff muscle imbalance on forceful internal impingement and peel-back of the superior labrum. A Cadaveric Study. Am J Sport Med 2009;37:2222-7. doi: 10.1177\%2F036354650 9337450

110. Meister K, Andrews JR. Classification and treatment of rotator cuff injuries in the overhead athlete. JOSPT 1993;18:413-421. doi: 10.2519/ jospt.1993.18.2.413

111. Wickham J, Pizzari T, Balster S, et al.. The variable roles of the upper and lower subscapularis during shoulder motion. Clin Biomech 2014;29:885-91. doi: 10.1016/j.clinbio mech. 2014.07.003

112. Kibler WB. The role of the scapula in athletic shoulder function. Am J Sport Med 1998;26:32537. doi: $10.1177 \% 2 F 03635465980260022801$

113. Voight ML, Thomson BC. The Role of the Scapula in the Rehabilitation of Shoulder Injuries, J Athl Train 2000;35:364-72.
114. Tsai N-T, McClure PW, Karduna AR. Effects of muscle fatigue on 3-dimensional scapular kinematics. Arch Phys Med Rehabil 2003;84:10005. doi: 10.1016/S0003-9993(03)00127-8

115. Ludewig PM, Cook TM. Alterations in shoulder kinematics and associated muscle activity in people with symptoms of shoulder impingement. Phys Ther, 2000;80:276-91. doi: 10.1093/ptj/80.3.276

116. Newmark J, Hochberg FH. "Doctor, it hurts when I play": painful disorders among instrumental musicians. Med Probl Perform Art 1987;2:93-7.

117. Kivi P. Rheumatic disorders of the upper limbs associated with repetitive occupational tasks in Finland in 1975-1979. Scand J Rheumatol 1984;13:101-7. doi: 10.3109/03009748409100371

118. Hadler NM, Gillings DB, Imbus HR, et al. Hand structure and function in an industrial setting: influence of three patterns of stereotyped, repetitive usage. Arthritis Rheum 1978;21:210-20. doi:10.1002/art.1780210206

119. Luopajarvi T, Kuorinka I, Virolainen M, Holmberg M. Prevalence of tenosynovitis and other injuries of the upper extremities in repetitive work. Scand J Work Environ Health 1979;5(Suppl):48-55.

120. Miller MH, Topliss DJ. Chronic upper limb pain syndrome (repetitive strain injury) in the Australian workforce: a systematic cross sectional rheumatological study of 229 patients. J Rheumatol 1988;15:1705-12.

121. Roto P, Kivi P. Prevalence of epicondylitis and tenosynovitis among meatcutters. Scand J Work Environ Health 1984;10:203-5.

122. Liu S, Hayden GF. Maladies in Musicians. South Med J 2002;95:727-34.

123. Toledo SD, Nadler SF, Norris RN, et al. Sports and performing arts Medicine. 5. Issues relating to musicians. Arch Phys Med Rehabil Suppl1 2004;85:S72-4. doi: 10.1053/j.apmr.2003.12.006

124. Abreu-Ramos AM, Micheo M. Lifetime prevalence of upper-body musculoskeletal problems in a professional-level symphony orchestra: age, gender, and instrument-specific results. Medical Problems of Performing Artists 2007;22:97-104.

Submission: May 8, 2020

Revision received: June 14, 2020 Accepted for publication: June 14, 2020 